\title{
Persepsi Bauran Pemasaran terhadap Kepuasan Konsumen dan Hubungannya dengan Minat Berkunjung Ulang pada Mangsi Coffee
}

\author{
NI WAYAN VIVI OVITA, \\ I G A OKA SURYAWARDANI, I DEWA GEDE AGUNG
}

\author{
Program Studi Agribisnis, Fakultas Pertanian, Universitas Udayana \\ Jl. PB. Sudirman Denpasar 80232 Bali \\ Email : viviovita96@gmail.com \\ gungdani@gmail.com
}

\section{Abstract \\ Perception of Marketing Mix on Consumer Satisfaction and The Relations with Intention to Revisit in Mangsi Coffee}

Mangsi Coffee is one coffee shop in Denpasar area, as one of the tourism facilities in Bali. Rapid market competition resulted in Mangsi needing to pay attention to customer satisfaction. Consumer satisfaction is measured through consumer perceptions by assessing the marketing strategies that have been applied. The purpose of this study is to identify indicators forming marketing mix variables that affect customer satisfaction and its relationship with intention to revisit in Mangsi Coffee. This research was conducted at Mangsi Coffee Sanur and Merdeka with 100 respondents. The analysis used is Structural Equation Model (SEM). The results showed that the product variable was formed by 5 brand indicators, taste, presentation, aroma, and product variation. Price variables are formed by 3 indicators, namely affordability, price suitability, and price competitiveness. Promotion variables are formed by 4 indicators of service, media, quality, and quantity of promotion. Place variables are formed by 4 indicators of comfort, decoration, cleanliness and service. The results of the direct influence of exogenous variables on endogenous variables with a significant level is 5\% (0.05) indicate that all direct relationships have a significant and positive effect. The influence of the most significant marketing mix variables on customer satisfaction is the promotion variable is $21.7 \%(0.217)$ with $\mathrm{p}$-Value is 0.065 . The effect of variable customer satisfaction on intention to revisit is $77.3 \%(0.773)$ with a p-Value is 0.000 . The results showed that consumer satisfaction at Mangsi Coffee was good but an evaluation of marketing strategy was needed if a marketing strategy was changed.

Keywords : marketing mix, perception, satisfaction, intention to revisit

\section{Pendahuluan}

\subsection{Latar Belakang}

Sektor pariwisata Bali merupakan sektor yang berkontribusi paling tinggi terhadap PDRB (Produk Domestik Regional Bruto) Bali dari tahun 2010-2016 dibandingkan sektor lainnya seperti pertanian, ekonomi dan lainnya. Menurut catatan BPS Bali, peran pariwisata terhadap PDRB pada tahun 2010 sebesar 19,12\% kemudian mengalami peningkatan hingga tahun 2016 sebesar 22,82\%. Sebaliknya, peran sektor pertanian 
terhadap PDRB semakin menurun dari tahun 2010 sebesar 17,17\% menjadi 14,74\% pada tahun 2010. Kontribusi sektor pariwisata yang tinggi di latarbelakangi oleh kunjungan wisatawan asing maupun domestik yang mengalami peningkatan tiap tahunnya. Peningkatan kunjungan wisatawan mancanegara ke Bali tahun 2006-2016 dapat dilihat pada tabel 1.

Tabel 1.

Kunjungan Wisatawan Mancanegara ke Bali pada Tahun 2006-2016

\begin{tabular}{ccc}
\hline Tahun & Kedatangan Wisatawan & Persentase Perubahan $(\%)$ \\
\hline 2006 & 1.262 .537 & $-9,10$ \\
2007 & 1.668 .531 & 32,16 \\
2008 & 2.085 .084 & 24,96 \\
2009 & 2.385 .122 & 14,39 \\
2010 & 2.576 .142 & 8,01 \\
2011 & 2.826 .709 & 9,73 \\
2012 & 2.949 .332 & 4,34 \\
2013 & 3.278 .598 & 11,16 \\
2014 & 3.766 .638 & 14,89 \\
2015 & 4.001 .835 & 6,24 \\
2016 & 4.927 .937 & 23,14 \\
\hline
\end{tabular}

Sumber: BPS Bali (2017)

Adanya peningkatan kunjungan setiap tahunnya perlu diikuti juga dengan peningkatan fasilitas wisata yang mendukung. Salah satu fasilitas wisata di Bali ialah Coffee Shop yang merupakan salah satu bentuk sinergitas antara sektor pertanian dan pariwisata yang dapat meningkatkan nilai jual kopi khususnya kopi Bali. Mangsi Coffee merupakan salah satu Coffee Shop yang terkenal di Bali dengan ciri khas produk kopi yang dijual berjenis arabika asli kopi kintamani. Mangsi Coffee berdiri dari tahun 2004 mulai dari kopi bubuk dalam kemasan, kopi dengan campuran rempah-rempah Bali hingga sekarang Mangsi Coffee merupakan Coffee Shop yang telah memiliki 5 cabang yang tersebar di Bali. Seiring berkembangannya waktu, kopi shop di Bali semakin bertambah yang mengakibatkan persaingan pasar pada kopi shop semakin pesat. Hal tersebut menjadi tantangan pemasaran bagi Mangsi Coffee, sehingga perlu dilakukan pengukuran tingkat kepuasan konsumen terhadap strategi pemasaran yang ditawarkan. Evaluasi strategi pemasaran dilakukan dengan melihat persepsi kepuasan konsumen terhadap bauran pemasaran.

\subsection{Rumusan Masalah}

Berdasarkan latarbelakang masalah diatas, maka dapat dirumuskan permasalahan sebagai berikut:

1. Apa saja indikator-indikator pembentuk variabel dalam bauran pemasaran produk kopi Mangsi Coffee?

2. Bagaimana pengaruh persepsi bauran pemasaran terhadap kepuasan konsumen dalam mengkonsumsi produk kopi Mangsi Coffee?

3. Bagaimana pengaruh kepuasan konsumen terhadap minat berkunjung ulang pada Mangsi Coffee? 


\subsection{Tujuan Penelitian}

Sesuai dengan perumusan masalah tersebut, maka tujuan penelitian ini, sebagai berikut:

1. Mengidentifikasi indikator-indikator pembentuk variabel dalam bauran pemasaran produk kopi Mangsi Coffee.

2. Mengetahui pengaruh persepsi bauran pemasaran terhadap kepuasan konsumen dalam mengkonsumsi produk kopi Mangsi Coffee.

3. Mengetahui pengaruh kepuasan konsumen terhadap minat berkunjung ulang pada Mangsi Coffee.

\section{Metodelogi Penelitian}

\subsection{Lokasi dan Waktu Penelitian}

Penelitian ini dilakukan pada Mangsi Coffee cabang Merdeka dan Cabang Sanur. Penelitian ini dilaksanakan selama 10 bulan yakni dari bulan September sampai Juni 2018. Waktu penelitian ini terhitung dari pengajuan judul sampai penelitian terselesaikan dalam bentuk skripsi.

\subsection{Data}

Sumber data dari penelitian ini adalah primer dan sekunder, dimana data primer diperoleh melalui secara langsung oleh peneliti melalui wawancara kuisioner dan data sekunder diperoleh dari buku-buku, maupun penelitian terdahulu yang dapat memperkuat data primer.

\subsection{Responden Penelitian dan Informan Kunci}

Responden dalam penelitian ini adalah konsumen yang datang ke Mangsi Coffee dan mengkonsumsi produk kopi dari Mangsi Coffee. Jumlah sampel dalam penelitian ini sebanyak 100 sampel yang terdiri dari 50 orang konsumen mancanegara dan 50 orang konsumen lokal. Penentuan sampel dilakukan sesuai dengan kriteria analisis data yang digunakan. Informan kunci pada penelitian ini adalah owner dari Mangsi Coffee yaitu dr. Made Windu Segara Senet, S.Ked.

\subsection{Pengumpulan Data}

Penelitian ini menggunakan beberapa metode pengumpulan data yaitu library research dan field research (wawancara, pengamatan langsung, dan kuisioner).

\subsection{Metode Analisis Data}

Data pada penelitian ini berupa pengukuran persepsi seseorang terhadap tingkat kepuasan yang tidak dapat diukur langsung dengan nilai. Menurut Sugiyono (2010) Skala likert dapat digunakan untuk mengukur sikap, pendapat, dan persepsi orang tentang fenomena sosial, sehingga data dalam penelitian ini diukur melalui Skala Likert. Hasil data yang diperoleh selanjutnya di analisis menggunakan metode analisis deskriptif. Analisis deskriptif digunakan untuk mendeskripsikan karakteristik responden dan gambaran umum perusahaan. Selain analisis deskriptif, penelitian ini juga menggunakan model persamaan struktural (Structural Equation Modelling/SEM)) berbasis varian, yang secara simultan dapat melakukan pengujian model pengukuran sekaligus pengujian model struktural. Model pengukuran (measurement model/outer model) bertujuan untuk menguji peranan indikator dalam merefleksikan variabel. Model 
struktural (structural model/inner model) bertujuan untuk menguji hubungan antara satu variabel dengan variabel lainnya baik hubungan langsung (direct effect) maupun hubungan tidak langsung (indirect effect).

\section{Hasil dan Pembahasan}

\subsection{Karakteristik Responden}

Responden penelitian berdasarkan karakteristik asal negara diperoleh bahwa, dari 50 orang responden mancanegara berasal dari 13 negara yaitu AS, Australia, Bulgaria, Cina, Hungarian, Inggris, Jepang, Jerman, Malaysia, Norwegia, Prancis, Russia, Tiongkok, sedangkan 50 orang responden lokal berasal dari Bali yaitu dari 3 kabupaten/kota antara lain Badung, Gianyar, Denpasar. Karakteristik responden berdasarkan periode kedatangan ke Bali bagi konsumen mancanegara didominasi oleh kedatangan yang lebih dari lima kali. Jika dilihat dari tempat tinggal responden mancanegara sebanyak 44\% tinggal di rumah milik sendiri, 32\% tinggal di villa dan 24 $\%$ tinggal di hotel. Karakteristik responden lokal berdasarkan tempat tinggal sebanyak $42 \%$ tinggal bersama orang tua, diikuti tinggal di rumah sendiri (24\%), tinggal di kontrakan (20\%) dan tinggal dikos (14\%). Konsumen yang mengkonsumsi kopi di dominasi oleh kaum laki-laki sebanyak 57\% yang didominasi oleh kalangan usia produktif sebesar $47 \%$.

\subsection{Hasil Analisis Uji Validitas}

Uji validitas suatu variabel dalam metode analisis model persamaan struktural berbasis varian dapat dilakukan dengan melihat nilai dari Convergent Validity dan Discriminant Validity. Uji validitas konvergen (convergent validity) dilakukan dengan melihat nilai loading faktor (outer loading) masing-masing indikator terhadap suatu variabel, dimana batas minimal yang digunakan ialah 0.5. Hasil ouput pengujian outer loading, menunjukkan bahwa seluruh indikator valid dengan nilai loading faktor diatas 0.5. Pada tabel 2 dapat dilihat hasil output uji validitas diskriminan.

Tabel 2.

\begin{tabular}{lcc}
\multicolumn{3}{c}{ Validitas Diskriminan } \\
\hline Variabel & AVE & VAVE \\
\hline Produk(PD) & 0,830 & 0,911 \\
Harga (HG) & 0,836 & 0,914 \\
Promosi (PM) & 0,862 & 0,929 \\
Tempat (TP) & 0,855 & 0,925 \\
Kepuasan (KP) & 0,860 & 0,928 \\
Minat (MN) & 0,881 & 0,939 \\
\hline \multicolumn{3}{l}{ Sumber: Data primer (2018) diolah }
\end{tabular}

Discriminant Validity merupakan perbandingan akar kuadrat dari Average Variance Extracted (AVE) untuk setiap variabel dengan korelasi antar variabel dalam model. Hasil output diatas menunjukkan bahwa keenam variabel memiliki nilai AVE berada diatas 0.5 dan nilai akar kuadrat AVE lebih tinggi dari pada korelasi variabel. 


\subsection{Hasil Analisis Uji Reliabilitas}

Reliabilitas variabel dapat dilihat dari nilai Cronbach Alpha dan nilai Composite Reliability dari masing-masing variabel. Suatu variabel dikatakan memiliki reliabilitas tinggi jika nilai Cronbach Alpha dan nilai Composite Reliability melebihi 0,7. Hasil output uji reliabilitas variabel dapat dilihat pada tabel 3.

Tabel 3.

Reliabilitas Variabel

\begin{tabular}{lcc}
\hline Variabel & Cronbachs Alpha & Composite Reliability \\
\hline Produk (PD) & 0,949 & 0,961 \\
Harga (HG) & 0,902 & 0,938 \\
Promosi (PM) & 0,947 & 0,962 \\
Tempat (TP) & 0,943 & 0,959 \\
Kepuasan (KP) & 0,946 & 0,961 \\
Minat (MN) & 0,932 & 0,957 \\
\hline
\end{tabular}

Sumber: Data Primer (2018) diolah

Tabel 3. menunjukkan bahwa seluruh variabel penelitian yang diuji memiliki nilai Cronbach Alpha dan Composite Reliability lebih besar dari 0,7 sehingga semua variabel telah memenuhi reliabilitas variabel yang baik.

\subsection{Analisis Konfirmatif}

Analisis konfirmatori pada penelitian ini ditujukkan untuk menarik inferensia mengenai peranan persepsi bauran pemasaran terhadap kepuasan konsumen dan minat berkunjung ulang pada Mangsi Coffee. Bauran pemasaran, kepuasan konsumen dan minat berkunjung ulang dimodelkan melalui model persamaan struktural (structural equation modeling/SEM) dengan melibatkan 6 variabel. Analisis konfirmatori terdiri dari analisis model pengukuran (Measurement / outer loading) dan analisis model structural (structural / inner model), dengan hasil output yang ditunjukkan pada gambar 1.

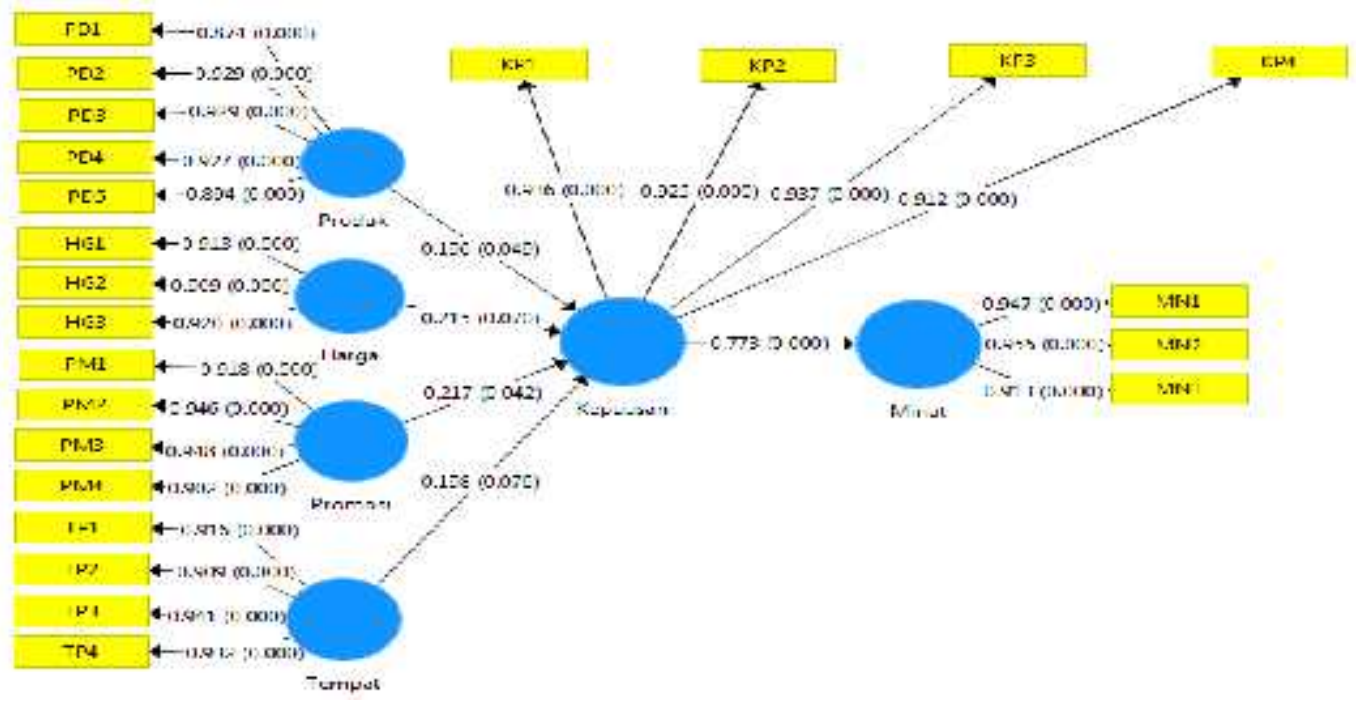

Gambar 1. Output Model Persamaaan Struktural 


\subsubsection{Hasil Analisis Model Pengukuran}

Analisis model pengukuran (outer/measurement model) menunjukkan peranan indikator-indikator dalam merefleksikan variabel yang dibentuk atau menunjukkan hubungan antara variabel dengan indikator-indikator penyusunnya. Hasil uji model pengukuran pada variabel produk menunjukkan bahwa indikator $\mathrm{PD}_{2}$ dan $\mathrm{PD}_{3}$ merupakan indikator dengan nilai loading terbesar. Hal ini mengindikasikan bahwa cita rasa dan penyajian yang diberikan oleh Mangsi Coffee merupakan penentu utama dari kualitas produk kopi Mangsi, diikuti oleh indikator $\mathrm{PD}_{4}$ (aroma).

Hasil output model pengukuran dari variabel harga menunjukkan indikator $\mathrm{HG}_{3}$ memiliki nilai loading terbesar dan $\mathrm{HG}_{2}$ memiliki nilai loading terkecil sebagai refleksi harga yang ditawarkan oleh Mangsi Coffee. Nilai loading indikator daya saing $\left(\mathrm{HG}_{3}\right)$ yang paling tinggi mengindikasikan bahwa Mangsi Coffee memiliki daya saing harga tinggi untuk menghadapi persaingan pasar yang semakin pesat dengan dibukaknya beberapa coffee shop pesaing.

Hasil model pengukuran variabel promosi seperti terlihat pada Gambar 3.2 menunjukkan kepercayaan pengunjung bahwa Mangsi Coffee mampu memberikan kualitas promosi yang yang baik $\left(\mathrm{PM}_{3}\right)$ memiliki nilai loading terbesar, sedangkan kuantitas promosi yang diberikan masih rendah dilihat dari nilai loading $\mathrm{PM}_{4}$. Hasil model pengukuran varibel tempat seperti terlihat pada Gambar 3.2 menunjukkan bahwa kebersihan tempat mampu memberikan kepuasan konsumen dengan nilai loading tertinggi (TP3), sedangkan dilihat dari dekorasi tempat memiliki nilai loading terendah sebagai refleksi dari variabel tempat.

Gambar 3.2 memperlihatkan seluruh indikator reflektif dari kepuasan konsumen memiliki nilai loading yang signifikan karena melebihi batas minimal nilai loading yaitu sebesar 0,7. Indikator KP3 yang menyatakan tingkat kepuasan konsumen terhadap promosi yang dilakukan Mangsi Coffee memiliki nilai loading tertinggi dan merupakan refleksi terbesar variabel ini. Indikator KP4 yang menyatakan kepuasan terhadap tempat Mangsi Coffee merupakan refleksi terkecil dari kepuasan konsumen dengan melihat nilai loading KP4 yang memiliki nilai paling rendah.

Satu-satunya variabel endogenus murni pada model persamaan struktural yang dibangun dalam penelitian ini adalah minat berkunjung ulang yang direfleksikan ke dalam tiga indikator. Hasil model pengukuran variabel minat berkunjung ulang terlihat pada Gambar 3.2 yang menunjukkan minat konsumen untuk datang kembali ke Mangsi Coffee direfleksikan dengan nilai loading tertinggi sebesar 0,947 dan minat untuk merekomendasikan Mangsi Coffee terefleksikan terendah sebesar 0,913. Meski demikian, ketiga indikator terbukti sangat signifikan sebagi refleksi dari minat berkunjung ulang pada Mangsi Coffee.

\subsubsection{Hasil Analisis Model Struktural}

Menurut Bollen (2002), analisis pada model struktural (inner/struktural model) dilakukan untuk memeriksa hubungan kausal antarvariabel dari model SEM yang dibangun. Nilai-nilai ini menunjukkan pengaruh-pengaruh langsung (direct effect) dari setiap variabel eksogenus terhadap variabel endogenus yang bersesuaian. Pada tabel 4 dapat dilihat pengaruh langsung antara variabel eksogenus terhadap variabel endogen. 
Tabel 4.

Pengaruh Langsung (Direct Effect)

\begin{tabular}{|c|c|c|c|c|c|c|c|}
\hline Hipotesis & \multicolumn{2}{|c|}{$\begin{array}{l}\text { Var. Eksogenus > Var. } \\
\text { Endogenus }\end{array}$} & \multirow{2}{*}{$\begin{array}{r}\begin{array}{c}\text { Koefisien } \\
\text { Jalur }\end{array} \\
0,196\end{array}$} & \multirow{2}{*}{$\begin{array}{c}\text { Standard } \\
\text { Error }\end{array}$} & \multirow{2}{*}{$\begin{array}{c}t- \\
\text { Statistic } \\
2,035\end{array}$} & \multicolumn{2}{|c|}{$p$-Value } \\
\hline $\mathrm{H} 1$ & Produk & > Kepuasan & & & & 0,043 & $* *$ \\
\hline $\mathrm{H} 2$ & Harga & > Kepuasan & 0,215 & 0,115 & 1,873 & 0,057 & $* *$ \\
\hline H3 & Promosi & > Kepuasan & 0,217 & 0,120 & 1,812 & 0,065 & $* *$ \\
\hline $\mathrm{H} 4$ & Tempat & > Kepuasan & 0,198 & 0,115 & 1,732 & 0,093 & $* *$ \\
\hline $\mathrm{H} 5$ & Kepuasan & $>$ Minat & & & & & \\
\hline & & $\begin{array}{l}\text { Berkunjung } \\
\text { Ulang }\end{array}$ & 0,773 & 0,052 & 1,903 & 0,000 & $* *$ \\
\hline
\end{tabular}

Sumber: Data Primer (2018) diolah

Tabel 4 menunjukkan secara jelas kelima hipotesis yang dikembangkan didukung secara nyata oleh hasil dari analisis model struktural yang dilakukan. Hasil pengaruh langsung variabel eksogen terhadap variabel endogen dengan taraf signifikan $5 \%(0,05)$ maka Ho ditolak jika nilai p-Value $<0,05$ dan hasil penelitian secara statistik adalah signifikan. Variabel produk berpengaruh langsung terhadap kepuasan konsumen dengan koefisien jalur 0,196 (positif) sudah signifikan dengan p-value sebesar 0,043, maka Ho ditolak yang berarti H1 diterima sehingga variabel produk berpengaruh positif dan signifikan terhadap kepuasan konsumen pada Mangsi Coffee. Artinya semakin meningkatnya kualitas produk pada Mangsi Coffee maka akan diikuti dengan semakin meningkatnya kepuasan konsumen. Variabel harga berpengaruh langsung terhadap kepuasan konsumen dengan koefisien jalur 0,215 (positif) sudah signifikan dengan pvalue sebesar 0,057 , maka Ho ditolak yang berarti $\mathrm{H}_{1}$ diterima sehingga variabel harga berpengaruh positif dan signifikan terhadap kepuasan konsumen pada Mangsi Coffee. Artinya semakin meningkatnya kualitas harga pada Mangsi Coffee maka akan diikuti dengan semakin meningkatnya kepuasan konsumen. Variabel promosi berpengaruh langsung terhadap kepuasan konsumen dengan koefisien jalur 0,217 (positif) sudah signifikan dengan p-value sebesar 0,065, maka Ho ditolak yang berarti $\mathrm{H}_{1}$ diterima sehingga variabel promosi berpengaruh positif dan signifikan terhadap kepuasan konsumen pada Mangsi Coffee. Artinya semakin meningkatnya kualitas promosi pada Mangsi Coffee maka akan diikuti dengan semakin meningkatnya kepuasan konsumen. Variabel tempat berpengaruh langsung terhadap kepuasan konsumen dengan koefisien jalur 0,198 (positif) sudah signifikan dengan p-value sebesar 0,093, maka Ho ditolak yang berarti $\mathrm{H}_{1}$ diterima sehingga variabel tempat berpengaruh positif dan signifikan terhadap kepuasan konsumen pada Mangsi Coffee. Artinya semakin meningkatnya kualitas tempat pada Mangsi Coffee maka akan diikuti dengan semakin meningkatnya kepuasan konsumen.

Selain pengaruh langsung dengan signifikansi hubungan ditunjukkan pada Gambar 1 terdapat beberapa jalur dimana sebuah variabel eksogenus juga memiliki pengaruh tak langsung terhadap variabel endogenus yang bersesuaian melalui mediasi variabel yang lain. Pada tabel 5, terdapat hasil output analisis pengaruh tak langsung. 
Tabel 5.

Pengaruh Tak Langsung

\begin{tabular}{lccccc}
\hline & $\begin{array}{c}\text { Outer Loading } \\
\text { of }(O)\end{array}$ & $\begin{array}{c}\text { Sample } \\
\text { Mean }(M)\end{array}$ & $\begin{array}{c}\text { Standard Deviation } \\
(\text { STDEV })\end{array}$ & $\begin{array}{c}\text { t-Statistics } \\
(\mid \text { OSTSTEV } \mid)\end{array}$ & $\begin{array}{c}p \text { - } \\
\text { Values }\end{array}$ \\
\hline $\mathrm{HG}>\mathrm{KP}>\mathrm{MN}$ & 0,166 & 0,171 & 0,097 & 1,707 & 0,044 \\
$\mathrm{PD}>\mathrm{KP}>\mathrm{MN}$ & 0,152 & 0,150 & 0,077 & 1,969 & 0,025 \\
$\mathrm{PM}>\mathrm{KP}>\mathrm{MN}$ & 0,168 & 0,167 & 0,090 & 1,859 & 0,032 \\
$\mathrm{TP}>\mathrm{KP}>\mathrm{MN}$ & 0,153 & 0,151 & 0,091 & 1,682 & 0,046 \\
\hline
\end{tabular}

Sumber: Data primer (2018) diolah

Tabel 5 memperlihatkan seluruh hubungan tak langsung. Koefisien jalur keempat pengaruh tak langsung masing-masing variabel harga $(0,166)$, variabel produk $(0,152)$, variabel promosi $(0,168)$, dan variabel tempat $(0,153)$ terhadap kepuasan konsumen melalui mediasi variabel laten minat berkunjung ulang, menunjukkan pengaruh yang signifikan pada taraf uji $=5 \%$. Kombinasi pengaruh langsung dengan pengaruh tak langsung membentuk pengaruh total sebuah laten eksogenus terhadap laten endogenus.

\subsection{Kelayakan dari Model Persamaan Struktural}

Analisis model persamaan struktural perlu dilakukan uji kelayakan model sebelum dilakukan interpretasi. Suryawardani (2018) dan Suryawardani et.al. (2017) setuju dengan pendapat beberapa peneliti (Fornell \&Larcker, 1981; Chin et al., 2003; Hair et al., 2012; Henseler et al., 2009) bahwa merekomendasikan agar kelayakan model diperiksa.

Tabel 6.

Reliabilitas Variabel

\begin{tabular}{llcccc}
\hline $\begin{array}{c}\text { Variabel } \\
\text { Laten }\end{array}$ & $\begin{array}{c}\text { Jenis } \\
\text { Variabel }\end{array}$ & $\begin{array}{c}\text { Jumlah } \\
\text { Indikator }\end{array}$ & $\begin{array}{c}\text { Composite } \\
\text { Reliability }(C R)\end{array}$ & $\begin{array}{c}\text { Average } \\
\text { Variance } \\
\text { Extracted }(\text { AVE) }\end{array}$ & $\mathrm{R}^{2}$ \\
\hline Produk & Eksogenus & 5 & 0,961 & 0,830 & $\mathrm{NA}^{\mathrm{a}}$ \\
Harga & Eksogenus & 3 & 0,938 & 0,836 & $\mathrm{NA}^{\mathrm{a}}$ \\
Promosi & Eksogenus & 4 & 0,962 & 0,862 & $\mathrm{NA}^{\mathrm{a}}$ \\
Tempat & Eksogenus & 4 & 0,959 & 0,855 & $\mathrm{NA}^{\mathrm{a}}$ \\
Kepuasan & Eksogenus / & 4 & 0,961 & 0,860 & 0,493 \\
& Endogenus & & & 0,881 & 0,597 \\
\hline Minat & Endogenus & 3 & 0,957 & $0.854^{\mathrm{b}}$ & 0.545 \\
\hline \multicolumn{7}{c}{ Rata-rata } & - & - &
\end{tabular}

Sumber: Data Primer (2018), diolah

Nilai $R$ square variabel kepuasan pelanggan adalah sebesar 0,493, hal ini menunjukkan bahwa model dengan variabel endogen kepuasan pelanggan (KP) memiliki kekuatan prediksi pada kategori moderat. Melalui model tersebut sebesar 49,3\% variansi variabel kepuasan pelanggan dapat dijelaskan oleh bauran pemasaran. Nilai $R$ square variabel minat berkunjung ulang adalah sebesar 0,597, hal ini menunjukkan bahwa model dengan variabel endogen minat berkunjung ulang (MN) memiliki kekuatan prediksi pada kategori moderat. Melalui model tersebut sebesar 59,7 $\%$ variansi variabel minat pembelian produk dapat dijelaskan oleh variabel kepuasan pelanggan. Kelayakan suatu model persamaan struktural secara utuh atau menghitung 
nilai Goodness of Fit (GoF) dari model bisa dilakukan dengan merujuk formula yang diperkenalkan oleh Tehenhaus et al. (2005) sebagai berikut:

$$
\mathrm{GoF}=\sqrt{\overline{\text { Communality }} \times \overline{R^{2}}}=\sqrt{\overline{A V E} \times \overline{R^{2}}}
$$

Persamaan diatas merupakan nilai rataan terbobot dengan bobot diperoleh dari jumlah indikator untuk setiap variabel laten. Menggunakan formula ini, maka GoF dari model dihitung sebesar 0,6822 , sebuah ukuran yang melebihi nilai ambang 0,50 untuk menyatakan model bisa diterima dan diinterpretasikan, sehingga interpretasi analisis bisa dilanjutkan.

\section{Kesimpulan dan Saran}

\subsection{Kesimpulan}

Variabel produk terbentuk oleh lima indikator yaitu merek, cita rasa, penyajian, aroma, dan variasi produk. Variabel harga terbentuk oleh tiga indikator yaitu keterjangkauan harga, kesesuaian harga dengan manfaat, dan daya saing harga. Variabel promosi terbentuk oleh empat indikator yaitu layanan, media, kualitas, dan kuantitas promosi. Variabel tempat dibentuk oleh empat indikator yaitu kenyamanan, dekorasi, kebersihan, dan kemudahan akses dan pelayanan.

Persepsi bauran pemasaran berpengaruh positif dan signifikan terhadap kepuasan konsumen, dari empat variabel bauran pemasaran variabel yang paling berpengaruh terhadap kepuasan konsumen ialah variabel promosi sebesar 21,7 \%. Pengaruh kepuasan konsumen terhadap minat berkunjung ulang posiyif dan signifikan sebesar $77,3 \%$.

\subsection{Saran}

Penelitian ini hanya mampu mengukur kekuatan model sebesar 49,3\% untuk pengaruh bauran pemasaran terhadap kepuasan konsumen, dan pengaruh kepuasan konsumen terhadap minat berkunjung ulang pada Mangsi Coffee sebesar 59,7\%. Hal ini dapat dijadikan sebagai peluang oleh peneliti selanjutnya untuk melakukan penelitian dengan model yang lebih baik dengan variansi variabel lain yang mempengaruhi kepuasan konsumen dan minat berkunjung ulang pada Mangsi Coffee. Sehingga nantinya didapatkan hasil model yang kuat.

\section{Ucapan Terimakasih}

Ucapan terimakasih penulis tujukan kepada para responden penelitian, pimpinan Mangsi Coffee dan semua pihak yang telah membantu pelaksanaan penelitian hingga karya ilmiah ini dapat dipublikasikan secara e-jurnal.

\section{Daftar Pustaka}

Bollen, K.A. 2002. Latent Variables in Psychology and the Social Sciences. Annual Review of Psychological, 53, pp.605-34.

BPS. 2017. Kunjungan Wisatawan Mancanegara ke Bali 2017. https://bali.bps.go.id/webbeta/website/brs_ind/brsInd-201709267073547.pdf (Diakses pada tanggal 4 Januari 2018, pukul 08.23).

BPS. 2017. Distribusi PDRB Provinsi Bali Menurut Lapangan Usaha (2010-2016). https://bali.bps.go.id/dynamictable/2017/03/20/76/distribusi-pdrb-provinsi bali- 
menurut-lapangan-usaha-2010---2016-persen-.html(Diakses pada tanggal 23 Januari 2018, pukul 13.45).

Ghozali, I. 2006. Aplikasi Analisis Multivariate dengan Sess. Cetakan Keempat. Semarang : Badan Penerbit Universitas Diponegoro.

Ghozali, I. 2011. Aplikasi Analisis Multivariate dengan Program IBM SPSS 19 (Edisi kelima). Semarang : Universitas Diponegoro.

Ghozali, I. 2014. Structural Equation Modelling Metode Alternatif dengan Partial Least Square Aplikasi. Cetakan Keempat. Semarang : Universitas Diponegoro.

Sudjana. 2005. Pengujian Validitas dan Uji Realibilitas Dalam Suatu Kuisioner. http://repository.upi.edu/2754/6/S_PEM_0802584_Chapter3.pdf (Diakses pada tanggal 19 Februari 2018 pukul 19.00)

Sugiyono. 2010. Metode Penelitian Kuantitatif Kualitatif dan R\&D. Bandung: CV Alfabeta.

Suryawardani, I G.A.O., and A.S Wiranatha.2018. Evaluation of Marketing Strategy of Sanur Village Festival Based on Visitors Behaviour. International Juornal of Applied Business and Economic Research. Vol.16, Number 2, 2018. Page: 261276.ISSN: 0972-7302

Suryawardani, I.G.A.O., A.S. Wiranatha, I.K.G. Bendesa, M. Antara and Mariam Gravari_Basbas.2017.A Struktural Model of Foreign Tourist Loyalty in Nature_based Tourist in Bali. International Journal of Bussiness and Economic Research. Volume 15 Number 19, page; 195-211. (2017). ISSN: 0972-7302

TripAdvisor. 2017. Destinasi Wisata Terbaik 2017 di Dunia. (Diakses pada tanggal 20 Januari 2018, pukul 17.55) 